\title{
On the study of phase formation and critical current density in superconducting $\mathrm{MgB}_{2}$
}

\author{
SUCHITRA RAJPUT, SUJEET CHAUDHARY*, SUBHASH C KASHYAP and \\ PANKAJ SRIVASTAVA
}

Department of Physics, Indian Institute of Technology Delhi, New Delhi 110 016, India

MS received 2 February 2006

\begin{abstract}
Superconducting bulk $\mathrm{MgB}_{2}$ samples have been synthesized by employing sintering technique without using any additional process steps, generally undertaken in view of the substantial loss of magnesium, during heat treatment. Starting with $\mathrm{Mg}$ rich powders having different atomic ratios of $\mathrm{Mg}: \mathrm{B}$, as against the nominally required $\mathrm{Mg}: \mathrm{B}=1: 2$ ratio, we have obtained superconducting $\mathrm{MgB}_{2}$ samples of different characteristics. The effect of excess $\mathrm{Mg}$ in the starting mixture and processing temperature on the phase-formation, transition temperature $\left(T_{\mathrm{C}}\right)$ and critical current density $\left(J_{\mathrm{C}}\right)$ have been investigated by electrical transport and a.c. susceptibility measurements. The $X$-ray diffraction and $X$-ray photoelectron spectroscopic analyses of $\mathrm{MgB}_{2}$ bulk samples have been carried out to understand the role of excess $\mathrm{Mg}$ and the effect of processing temperature. It is established that $\mathrm{MgB}_{2}$ samples with high critical current density can be synthesized from a $\mathrm{Mg}$ rich powder having $\mathrm{Mg}: \mathrm{B}$ in $2: 2$ ratio, at temperatures around $790^{\circ} \mathrm{C}$. Critical current density has been found to vary systematically with processing temperature.
\end{abstract}

Keywords. $\mathrm{MgB}_{2}$; transition temperature; X-ray photoelectron spectroscopy.

\section{Introduction}

The observation of superconductivity at high transition temperature $\left(T_{\mathrm{C}}\right)$ of $39 \mathrm{~K}$ (which is nearly twice the highest $T_{\mathrm{C}}$ recorded for any intermetallic compound) in $\mathrm{MgB}_{2}$, in 2001 (Nagamatsu et al 2001), had sparked renewed interest in the study of superconductivity in non-cuprate materials. Potential large scale applications of $\mathrm{MgB}_{2}$ in different morphologies, including bulk (Kumakura et al 2001; Botta et al 2002; Bud'ko et al 2002; Cardwell et al 2002), single crystal, wires, tapes (Cardwell et al 2002) and thin films (Buzae and Yamashita 2001), are envisaged primarily due to its relatively high transition temperature, better mechanical properties (Feng et al 2004), weak-link free grain boundaries (Jin et al 2001), high transport critical current density, $J_{\mathrm{C}}$ (Buzae and Yamashita 2001; Canfield et al 2001), large coherence lengths (Welp et al 2003) and simple crystal structure (King et al 2002; Cava et al 2003).

In spite of the chemical and structural simplicity, the synthesis of stoichiometric $\mathrm{MgB}_{2}$ has so far proved to be very difficult. The vapourization of $\mathrm{Mg}$ and its affinity for oxygen is the main difficulty encountered in the synthesis of $\mathrm{MgB}_{2}$. Liu et al (2001) found that the $\mathrm{MgB}_{2}$ phase is thermodynamically stable only under high $\mathrm{Mg}$ partial pressure. If the $\mathrm{Mg}$ overpressure is too low, the decom-

*Author for correspondence (sujeetc@ physics.iitd.ernet.in) position of $\mathrm{MgB}_{2}$ is thermodynamically favoured, whereas if it is too high, $\mathrm{Mg}$ condenses on $\mathrm{MgB}_{2}$ itself. It is reported that superconducting bulk $\mathrm{MgB}_{2}$ samples are synthesized by sintering a compressed pellet of $\mathrm{Mg}$ and $\mathrm{B}$ powders either in vacuum or in Ar atmosphere (Cardwell et al 2002). A few groups have synthesized superconducting $\mathrm{MgB}_{2}$ either by hot-press sintering a stoichiometric mixture of Mg and B powders (Shen et al 2003; Drozd et al 2004), or by covering the starting powder mixture in Ta foil followed by sealing in a quartz or Nb-lined stainless steel container (Kumakura et al 2001; Botta et al 2002; Cardwell et al 2002). Since the above researchers have employed additional steps to arrest the evaporation of $\mathrm{Mg}$, hence an approach, which compensates for the vapourization of $\mathrm{Mg}$, and leads to the formation of $\mathrm{MgB}_{2}$ with improved superconducting properties should be attempted. Both from technical and scientific point of view, it becomes important to study the effect of various synthesis parameters and starting composition on the $\mathrm{MgB}_{2}$ phase formation and the critical current density. The use of excess $\mathrm{Mg}$ (only in the limited range) on superconducting properties of $\mathrm{MgB}_{2}$ has been investigated (Ribeiro et al 2003). In this paper, we report the preparation of $\mathrm{MgB}_{2}$ bulk samples in a single step without involving cumbersome steps of evacuation of ampoule or high pressure sintering, etc. The transition temperature is determined from both the magnetic a.c. susceptibility measurement as well as electrical transport measurement. 


\section{Experimental}

Four sets of polycrystalline bulk samples of $\mathrm{MgB}_{2}$ were prepared by heat treating the pellets formed from different mixtures of magnesium (99.8\%, Strem chemicals) and boron $(99.9 \%$, Cerac) powders with starting composition equivalent to $\mathrm{Mg}_{x} \mathrm{~B}_{2}$, where $x=1.25,1.5,1.75$ and 2.0 (named as MB1, MB2, MB3 and MB4, respectively).

Thoroughly ground mixture of $\mathrm{Mg}$ and $\mathrm{B}$ was compressed uniaxially at a pressure of $\approx 750 \mathrm{MPa}$ to form pellets of $5 \mathrm{~mm}$ diameter. These pellets were kept on the alumina plates and buried under a heap of $\mathrm{Mg}$ powder before subjecting to heat treatment. The pellets of each set were heat treated at various temperatures under Ar atmosphere. A ramping rate of $5^{\circ} \mathrm{C} / \mathrm{min}$ was maintained using a programmable box-furnace (Model-K1252, Heraeus) for increasing the temperature to the hold temperature, $T_{\mathrm{h}}$, at which the samples were maintained for $1 \mathrm{~h}$ in all the cases. The hold temperature was varied in the range $500-920^{\circ} \mathrm{C}$. The samples were then quenched in air. The a.c. susceptibility $\left(\chi_{\text {a.c. }}=\chi^{\prime}{ }_{\text {a.c. }}+i \chi^{\prime \prime}{ }_{\text {a.c. }}\right)$ measurement was carried out at different temperatures by a very sensitive (home-made) a.c. susceptometer in an a.c. field of $\sim 250 \mathrm{mOe}$ (unless otherwise stated) at $540 \mathrm{~Hz}$ using a closed cycle He-cryostat and a lock-in-amplifier which separated the in-phase and out-of-phase signals of the complex $\chi_{\text {a.c. }}(T)$. Both the $\chi_{\text {a.c. }}-T$ and $\rho-T$ data were recorded while warming the samples at a slow rate of $0.25 \mathrm{~K} / \mathrm{min}$ to ensure thermal equilibrium between the sample and the sensor. The X-ray diffraction data on these samples were acquired by employing a $12 \mathrm{~kW}$ rotating anode, Rigaku X-ray diffractometer. The X-ray photoelectron spectra were recorded on a Thermo VG Scientific MultiLab 2000 X-ray photoelectron spectrophotometer, using $\mathrm{Mg} \mathrm{K} \alpha(1253.6 \mathrm{eV})$ as an excitation source.

\section{Results and discussion}

In view of the high volatility of $\mathrm{Mg}$ during the synthesis of $\mathrm{MgB}_{2}$, existence of a finite window for thermodynamically stable $\mathrm{MgB}_{2}$ in the phase diagram when $\mathrm{Mg}$ overpressure is high, and the fact that among the known compounds of the $\mathrm{Mg}-\mathrm{B}$ system i.e. $\mathrm{MgB}_{2}, \mathrm{MgB}_{4}, \mathrm{MgB}_{6}$, $\mathrm{MgB}_{7}$ and $\mathrm{MgB}_{12}, \mathrm{MgB}_{2}$ is clearly the most $\mathrm{Mg}$-rich (binary) compound (Massalski 1990), it was decided to take $\mathrm{Mg}$ in excess of stoichiometric requirement (33.33\%) in the starting mixture of $\mathrm{Mg}$ and B powders. The MB1-MB4 samples were therefore prepared by having monotonically increasing amount of excess $\mathrm{Mg}$ in the starting mixture (from $38.5 \mathrm{a} / \mathrm{o}$ to $50 \mathrm{a} / \mathrm{o}$ ). Furthermore, the pellets were buried under a heap of $\mathrm{Mg}$ powder.

From the $\chi_{\text {a.c. }}-T$ measurement carried out on these samples prepared at different hold temperatures, it was found that none of the samples of MB1 and MB2 sets, having starting compositions of $\mathrm{Mg}: \mathrm{B}=1 \cdot 25: 2$ (i.e. $38 \cdot 5 \mathrm{a} / \mathrm{o}$ ) and
$\mathrm{Mg}: \mathrm{B}=1 \cdot 5: 2$ (i.e. $42 \cdot 8 \mathrm{a} / \mathrm{o}$ ), respectively, were superconducting. On further increase in the $\mathrm{Mg}$ ratio (i.e. $46 \cdot 6$ $\mathrm{a} / \mathrm{o}(\mathrm{Mg}: \mathrm{B}=1.75: 2)$ in MB3 set), only those samples which were prepared at a hold temperature lying in the range $650-760^{\circ} \mathrm{C}$ exhibited superconducting transition. The samples of MB4 set having $50 \mathrm{a} / \mathrm{o}$ of $\mathrm{Mg}$ (most $\mathrm{Mg}$ rich, i.e. $\mathrm{Mg}: \mathrm{B}=2: 2$ ) are superconducting (see figure 1) even when synthesized over a wider range of hold temperature i.e. $T_{\mathrm{h}}=550-900^{\circ} \mathrm{C}$ with $T^{\mathrm{p}} \mathrm{C}(\chi-T)$ lying in the range of $39.2 \pm 0 \cdot 2-40 \cdot 7 \pm 0.5 \mathrm{~K}$, with a transition width $(\Delta T)$ of $\leq 1.0 \mathrm{~K}$. Here, $T^{\mathrm{p}} \mathrm{C}(\chi-T)$ is defined as the temperature at which $\chi^{\prime \prime}(T)$ exhibits a maximum. When the processing temperature was kept below $550^{\circ} \mathrm{C}$, no superconductivity was observed down to the lowest investigated temperature of $\approx 15 \mathrm{~K}$, in MB4 samples. On the higher side of hold temperature i.e. $T_{\mathrm{h}}>900^{\circ} \mathrm{C}$, the resulting samples were mechanically too crumbly to make any measurement. This is in agreement with the observation of Jin et al (2001) who reported the formation of porous samples (and the loss of $60 \%$ of $\mathrm{Mg}$ ) at $900^{\circ} \mathrm{C}$. It is thus evident that the $100 \%$ increase of excess $\mathrm{Mg}$ in the starting mixture (set MB4) led to superconducting samples when sintered over a wider range of $550-900^{\circ} \mathrm{C}$.

The critical current density $\left(J_{\mathrm{C}}\right)$ of the samples of set MB4, sintered at different temperatures, has been calculated using modified Bean's critical state model (Beans 1962; Chen et al 1989; Clem 1994). Figure 2 shows $J_{\mathrm{C}}(T)$ behaviour of the $\mathrm{MgB}_{2}$ samples synthesized at $T_{\mathrm{h}}$ of 550 , 790,850 and $870^{\circ} \mathrm{C}$ with the estimated transition temperature, $T_{\mathrm{p}}$. For all the samples, the estimated/extrapolated $J_{\mathrm{C}}$ at $37.5 \mathrm{~K}$ is more than $10^{7} \mathrm{~A} / \mathrm{m}^{2}$. Further, the sample synthesized at $790^{\circ} \mathrm{C}$ exhibited highest $J_{\mathrm{C}}$ of $1.5 \times 10^{7} \mathrm{~A} / \mathrm{m}^{2}$ at $39.6 \mathrm{~K}$. It is, therefore, noted that $790^{\circ} \mathrm{C}$ is the most suitable synthesis temperature for preparing $\mathrm{MgB}_{2}$ from a starting mixture having $100 \%$ excess of $\mathrm{Mg}$.

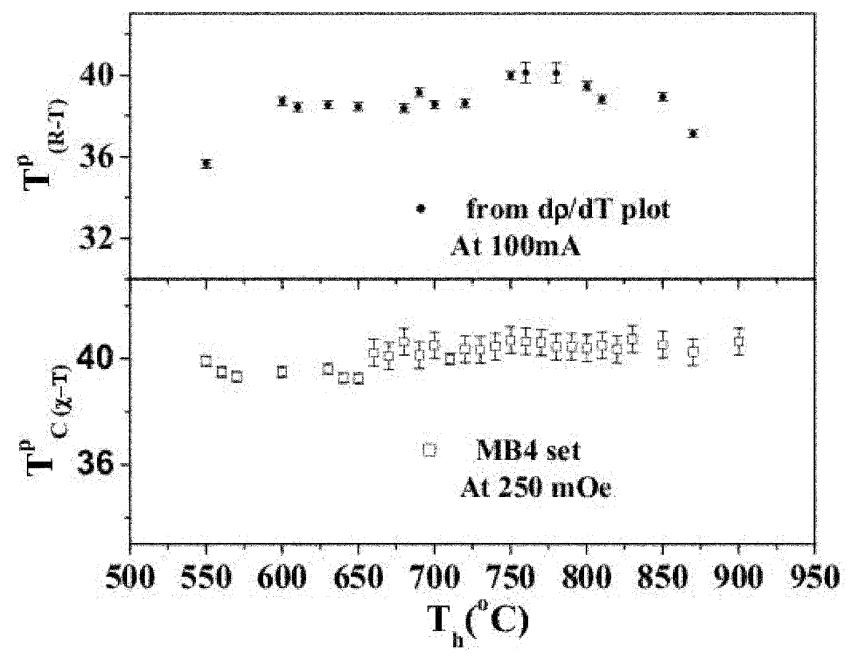

Figure 1. Variation of $T^{\mathrm{p}}{ }_{\mathrm{C}(R-T)}$ (upper panel) and $T^{\mathrm{p}}{ }_{\mathrm{C}(\chi-T)}$ (lower panel) with sintering temperature for the $\mathrm{MgB}_{2}$ samples from MB4 batch $\left(\mathrm{Mg}_{2-x} \mathrm{~B}_{2}, x=0\right)$. All these samples are quenched to room temperature after a hold time of $1 \mathrm{~h}$. 
The X-ray diffractograms (XRD) of various $\mathrm{MgB}_{2}$ samples from MB4 set have been analysed for correlating the formation of various phases with the increase in processing temperature. For the sake of brevity, we show in figure 3, diffractograms of the samples synthesized at 630 , $700,790,810$ and $850^{\circ} \mathrm{C}$. It may be noted that the samples prepared at 630 and $700^{\circ} \mathrm{C}$ possess additional phases, viz. $\mathrm{Mg}$ and $\mathrm{MgO}$. This could be due to the excess $\mathrm{Mg}$ taken in the starting powder mixture. The absence of peaks corresponding to $\mathrm{Mg}$ in the diffractograms of the samples sintered at $790^{\circ} \mathrm{C}$ and up to $\sim 870^{\circ} \mathrm{C}$ reveals the complete consumption of $\mathrm{Mg}$ in the formation of the diboride phase. The presence of peaks corresponding to the rem-

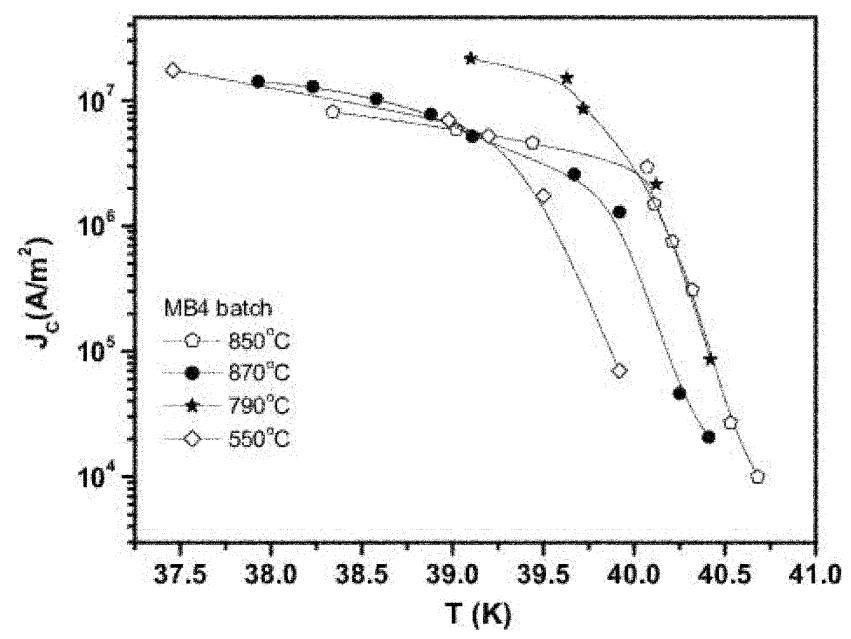

Figure 2. $J_{\mathrm{C}}$ vs $T$ curves for $\mathrm{MgB}_{2}$ samples from $\mathrm{MB} 4$ set sintered at $550,790,850$, and $870^{\circ} \mathrm{C}$.

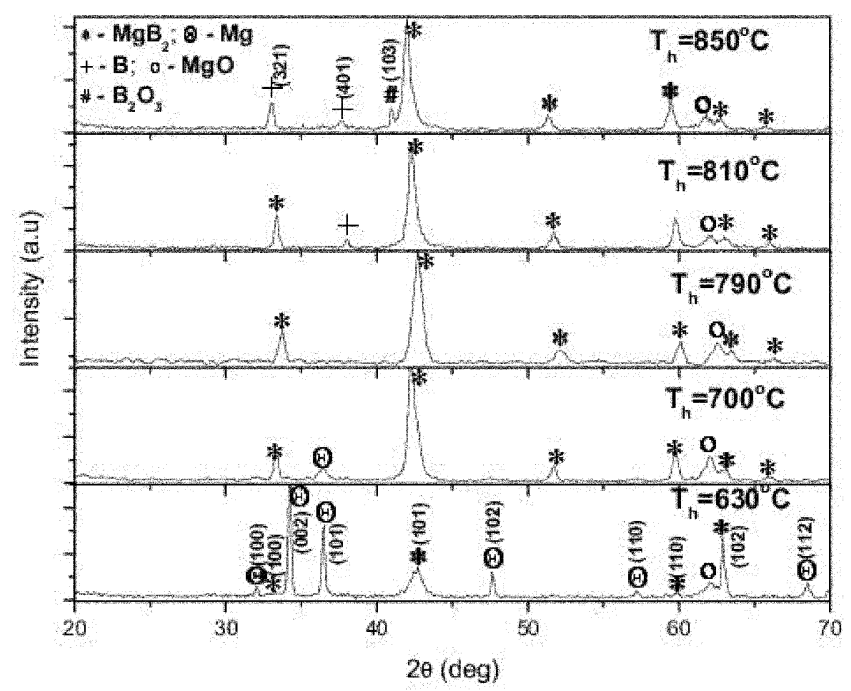

Figure 3. X-ray diffraction patterns for the $\mathrm{MgB}_{2}$ pellets sintered at $630,700,790,810$ and $850^{\circ} \mathrm{C}$. The sample sintered at $790^{\circ} \mathrm{C}$ is found to have lesser impurities than those sintered at lower and higher temperatures. nant $\mathrm{B}$ in the XRD patterns of samples prepared at 810 and $850^{\circ} \mathrm{C}$ clearly support this view. These results indicate that at higher $T_{\mathrm{h}}$, all the $\mathrm{Mg}$ is consumed in the formation of $\mathrm{MgB}_{2}$ besides its vapourization (m.p. of $\mathrm{Mg}, 650^{\circ} \mathrm{C}$ ). The sample prepared at $790^{\circ} \mathrm{C}$ has maximum fraction of $\mathrm{MgB}_{2}$ with $\mathrm{MgO}$ as the only additional phase, and none of the constituents is detected in the elemental form. All these diffractograms reveal the formation of $\mathrm{MgO}$ too. This is understandable as the heating process was carried out in flowing $\mathrm{Ar}$ (without vacuum sealing). These $\mathrm{MgO}$ particles act as effective pinning centres, since the average particle size of $\mathrm{MgO}$ was estimated to lie between 70-150 A using Debye-Scherrer formula, which is comparable to the coherence length in $\mathrm{MgB}_{2}$ [ $100 \AA$, (Welp et al 2003)].

XPS analysis has also been undertaken for the samples of MB4 batch to strengthen the qualitative phase analysis drawn from XRD. The core level $\mathrm{Mg}-2 p$ and $\mathrm{B}-1 s$ XPS spectra, recorded for a few representative $\mathrm{MgB}_{2}$ samples
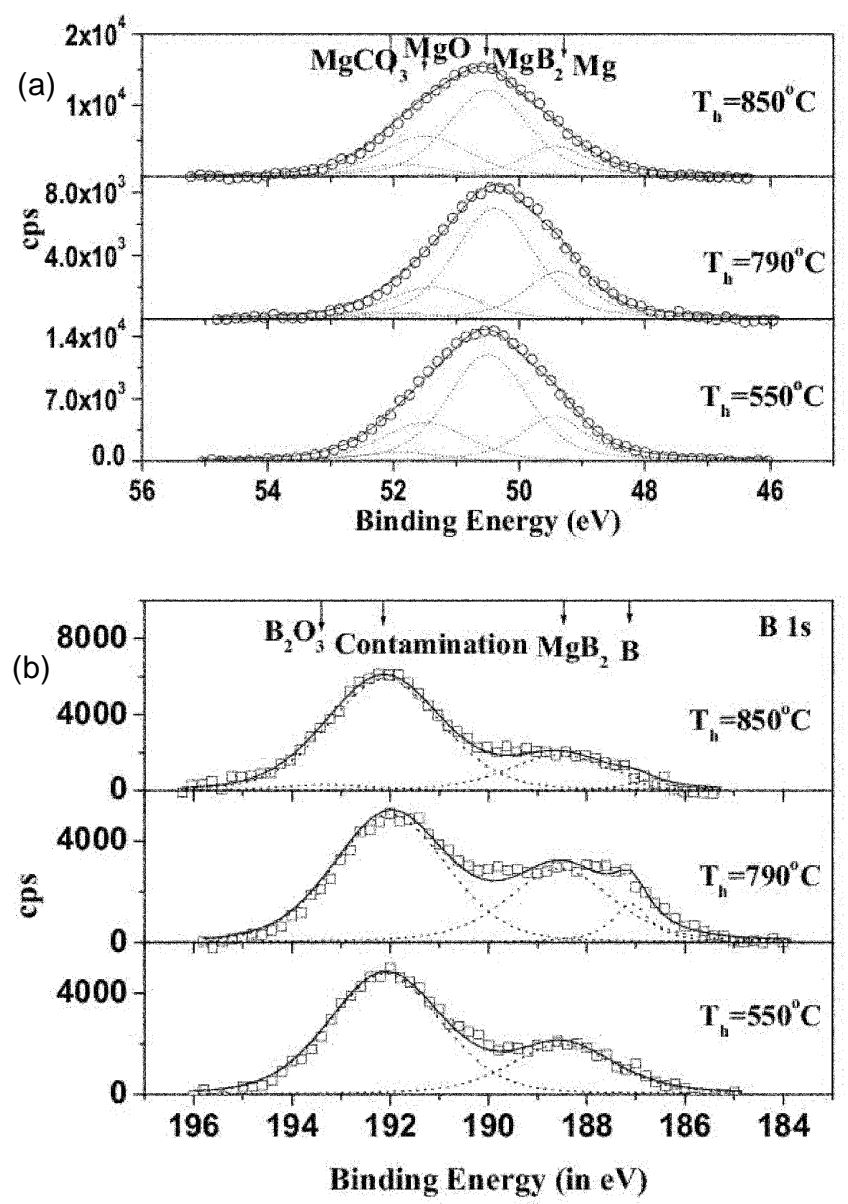

Figure 4. Core level spectra of the observed (a) $\mathrm{Mg}-2 p$ and (b) $\mathrm{B}-1 s$ peaks together with the fitted curves having both the gaussian and Lorentzian components, for samples sintered at $550^{\circ} \mathrm{C}, 790^{\circ} \mathrm{C}$ and $850^{\circ} \mathrm{C}$ from MB4 batch (whereas the symbols represent the experimental spectrum, the dotted lines indicate the component-peak used for overall curve fitting of the resulting peak shown by the solid line. The various peaklocations have been appropriately indicated by vertical-arrows). 
Table 1. Observed and reported binding energies of $\mathrm{Mg}-2 p$ and $\mathrm{B}-1 s$ electrons in $\mathrm{Mg}, \mathrm{MgB}_{2}, \mathrm{MgO}$, contamination and other oxides in $\mathrm{B}$, and $\mathrm{B}_{2} \mathrm{O}_{3}$ for samples synthesized from MB4 set at $550^{\circ} \mathrm{C}, 790^{\circ} \mathrm{C}$ and $850^{\circ} \mathrm{C}$, respectively.

\begin{tabular}{|c|c|c|c|}
\hline $\begin{array}{l}\text { Core } \\
\text { level }\end{array}$ & $\begin{array}{l}\text { Source/ } \\
\text { compound }\end{array}$ & $\begin{array}{l}\text { Reported BE } \\
(\mathrm{eV})\end{array}$ & $\begin{array}{c}\text { Observed BE } \\
(\mathrm{eV})\end{array}$ \\
\hline \multirow[t]{4}{*}{$\mathrm{Mg}-2 p$} & $\mathrm{Mg}$ & $\begin{array}{c}49 \cdot 2-49 \cdot 9 \\
\text { (Wagner } \text { et al } 1979)\end{array}$ & $49 \cdot 4-49 \cdot 5$ \\
\hline & $\mathrm{MgB}_{2}$ & $\begin{array}{c}50 \cdot 54 \\
\text { (Wagner } \text { et al 1979) }\end{array}$ & $50 \cdot 4-50 \cdot 6$ \\
\hline & $\mathrm{MgO}$ & $\begin{array}{c}51 \cdot 5 \\
\text { (Jariwala } \text { et al 2003) }\end{array}$ & $51 \cdot 4-51 \cdot 6$ \\
\hline & $\mathrm{MgCO}_{3}$ & $\begin{array}{c}51.9 \\
\text { (Crist 1999) }\end{array}$ & $51 \cdot 9$ \\
\hline \multirow[t]{4}{*}{$\mathrm{B}-1 s$} & B & $\begin{array}{c}186 \cdot 9-187 \cdot 5 \\
\text { (Wagner et al } 1979)\end{array}$ & $187 \cdot 0-18 \cdot 1$ \\
\hline & $\mathrm{MgB}_{2}$ & $\begin{array}{c}188 \cdot 2 \\
\text { (Garg et al 2004) }\end{array}$ & $188 \cdot 5-188 \cdot 55$ \\
\hline & $\begin{array}{c}\text { Other } \\
\text { contamination }\end{array}$ & $\begin{array}{c}191 \cdot 4,193 \cdot 2 \\
\text { (Aswal et al 2002) }\end{array}$ & $192 \cdot 1-192 \cdot 2$ \\
\hline & $\mathrm{B}_{2} \mathrm{O}_{3}$ & $\begin{array}{c}193 \cdot 3 \\
\text { (Aswal et al 2002) }\end{array}$ & $193 \cdot 3$ \\
\hline
\end{tabular}

(two at the extreme ends and one in the middle of the processing temperature) are presented in figure 4 . The core level spectrum of a multivalent element in a sample will generally exhibit a broad peak, which can be deconvoluted to identify different chemical states of the element in question. The observed $\mathrm{Mg}-2 p$ peaks in various spectra have been resolved into four peaks (table 1) with their maxima at 49.4-49.5, 50.4-50.6, 51.4-51.6 and $51.9 \mathrm{eV}$. The peak at $49.4 \mathrm{eV}$ corresponds to $2 p$-electrons in metallic magnesium (Wagner et al 1979), while the other three peaks at higher $\mathrm{BE}$ values i.e. at 50.4-50.6, 51.4-51.6 and $51.9 \mathrm{eV}$, can be attributed to the presence of $\mathrm{MgB}_{2}, \mathrm{MgO}$ and $\mathrm{MgCO}_{3}$ (Crist 1999; Jariwala et al 2003), respectively. Likewise a broad B- $1 s$ peak in the XP spectra (figure $4 \mathrm{~b}$ ) has been deconvoluted into a number of peaks appearing at $187-187 \cdot 1,188 \cdot 5-188 \cdot 55,192 \cdot 1-192 \cdot 2$ and $193 \cdot 3 \mathrm{eV}$, respectively. These peaks correspond to unreacted $\mathrm{B}, \mathrm{MgB}_{2}, \mathrm{~B}_{2} \mathrm{O}_{3}$ and other contaminants of $\mathrm{B}$ (Wagner et al 1979; Aswal et al 2002; Garg et al 2004), respectively. McGuinness et al (2001) also reported two additional peaks at 191.4 and 193.2 , besides the main peak in their Boron-K-edge NEXAFS for the samples of $\mathrm{MgB}_{2}$ and ascribed those to $\mathrm{B}_{2} \mathrm{O}_{3}$ and other contaminants of B. Similarly, Zhu et al (2002) and McGuinness et al (2001) reported the presence of extra peaks at 191.7 and $193.6 \mathrm{eV}$. Other workers (Foo et al 1991; Vasquez et al 2001) also observed the extra peaks in $\mathrm{B}-1 s$ spectrum and ascribed those to $\mathrm{B}_{2} \mathrm{O}_{3}$, sub-oxides and hydroxides of boron.

It can be seen that at $790^{\circ} \mathrm{C}, \mathrm{MgB}_{2}$ phase is formed predominantly along with reduced fraction of $\mathrm{MgO}$, which is in reasonable agreement with the observed XRD results. The observation of the $\mathrm{Mg}-2 p$ peak corresponding to pure $\mathrm{Mg}$ in all the three investigated samples is in contrast with the XRD observations (see figure 3 ). This could well be due to the slight degradation of the sample surface leading to $\mathrm{Mg}$-enrichment, as is also reported previously (Aswal et al 2002). The absence of peak at $187 \mathrm{eV}$ in the B-1s spectra (figure $4 \mathrm{~b}$ ) for the samples synthesized at $550^{\circ} \mathrm{C}$ shows complete consumption of $\mathrm{B}$ (which is expected as the $\mathrm{Mg}$ was in excess in these samples from MB4 batch). At $790^{\circ} \mathrm{C}$, however, unreacted B appears whose concentration decreases with increase in $T_{\mathrm{h}}$ to $850^{\circ} \mathrm{C}$, due to the formation of $\mathrm{B}_{2} \mathrm{O}_{3}$. Thus, for samples of MB4 batch, the processing temperature, $\sim 790^{\circ} \mathrm{C}$, is most suitable for the synthesis of $\mathrm{MgB}_{2}$ samples with improved superconducting properties. This clearly demonstrates the essential requirement of excess $\mathrm{Mg}$ in the starting mixture in this simple and economic synthesis technique.

\section{Conclusions}

Starting with $100 \%$ excess magnesium in the mixture of $\mathrm{Mg}$ and $\mathrm{B}$ and without requiring the sealing of the starting powder mixture either in quartz ampoules or $\mathrm{Ta} / \mathrm{Nb}$ liners it has been possible to form magnesium diboride phase having optimal superconducting characteristics. The best samples having maximum fraction of $\mathrm{MgB}_{2}$ and exhibiting superconducting transition at $40.5 \mathrm{~K}$ with $\Delta T=0.6 \mathrm{~K}$ were prepared by heat treating the $\mathrm{Mg}$ rich pellets $(\mathrm{Mg}: \mathrm{B}:: 2: 2)$ in flowing $\mathrm{Ar}$ at $790^{\circ} \mathrm{C}$ for $1 \mathrm{~h}$. The maximum critical current density, estimated from the a.c. susceptibility data, is found to be $1.5 \times 10^{7} \mathrm{~A} / \mathrm{m}^{2}$ at $39.6 \mathrm{~K}$. From both XPS and XRD results, it is found that the processing temperature of $790^{\circ} \mathrm{C}$ is optimum for the formation of $\mathrm{MgB}_{2}$ phase from a starting mixture having $100 \%$ excess of $\mathrm{Mg}$.

\section{Acknowledgement}

The authors thank A Lohani, Department of Physics, Indian Institute of Technology Bombay, Mumbai, for X-ray photoelectron spectroscopic measurements.

\section{References}

Aswal D K, Muthe K P, Tawde S, Chodhury S, Bagkar N, Singh A, Gupta S K and Yakhmi J V 2002 J. Cryst. Growth 236661

Beans C P 1962 Phys. Rev. Lett. 8250

Botta D et al 2002 Physica C369 232

Bud'ko S L, Canfield P C and Kogan V G 2002 Physica C382 85

Buzae C and Yamashita T 2001 Supercond. Sci. Technol. 14 R115

Canfield P C, Finnemore D K, Bud'ko S L, Ostenson J E, Lapertot G, Cunningham C E and Petrovic C 2001 Phys. Rev. Lett. 862423 
Cardwell D A, Hari Babu N, Kambara M and Campbell A M 2002 Physica C312 1262

Cava R J, Zandbergen H W and Inumaru K 2003 Physica $\mathbf{C 3 8 5}$ 8

Chen D-X, Nogues J and Rao K V 1989 Cryogenics 29800

Clem J R 1994 Phys. Rev. B50 9355

Crist B V 1999 Handbook of elements and native oxides (XPS International, Inc.) Vol. 1

Drozd V A, Gabovich A M, Gierlowski P, Pekala M and Szymezak H 2004 Physica $\mathbf{C 4 0 2} 325$

Feng Q R et al 2004 cond-mat/0408597

Foo W C, Ozcomert J S and Ternary M 1991 Surf. Sci. 255 245

Garg K B, Chatterji T, Dalela S, Heinonnen M, Leiro J, Dalela B and Singhal R K 2004 Solid State Commun. 131343

Jariwala C et al 2003 Phys. Rev. B68 174506

Jin S, Mavoori H, Bower C and Dover R B 2001 Nature 411 563

King R B 2002 Polyhedron 212347
Kumakura H, Takano Y, Fujii H, Togano K, Kito H and Ihara $\mathrm{H}$ 2001 Physica C363 179

Liu Z-K, Schlom D G, Li Q and Xi X X 2001 Appl. Phys. Lett. 783678

Massalski T 1990 Binary alloy phase diagrams (Materials Park, OH: ASM International) 2nd ed.

McGuinness C et al 2001 Europhys. Lett. 56112

Nagamatsu J, Nakagawa N, Muranaka T, Zenitani Y and Akimitsu J 2001 Nature $\mathbf{4 1 0} 63$

Ribeiro R A, Bud'ko S L, Petrovic C and Canfield P C 2003 Physica $\mathbf{C 3 8 5} 16$

Shen J-Q, Fang M-H, Zheng Y, Wang H T, Lu Y and Xu Z-A 2003 Physica C386 663

Vasquez R P 2001 Phys. Rev. B64 052510

Wagner C D, Riggs W M, Davis L E and Moduler J F 1979 Handbook of X-ray photoelectron spectroscopy (ed.) G E Muilenberg (Minnesota: Perkin-Elmer Corporation)

Welp U et al 2003 Physica $\mathbf{C 3 8 5} 154$

Zhu Y et al 2002 Phys. Rev. Lett. 88247002 